\title{
The effects of birth weight and postnatal linear growth retardation on blood pressure at age 11-12 years
}

\author{
S P Walker, P Gaskin, C A Powell, F I Bennett, T E Forrester, S Grantham-McGregor
}

\begin{abstract}
Study objective-To determine the effects of birth weight and linear growth retardation (stunting) in early childhood on blood pressure at age 11-12 years.

Design-Prospective cohort study.

Setting-Kingston, Jamaica.

Participants-112 stunted children

(height for age $<-2$ SD of the NCHS references) and 189 non-stunted children (height for age $>-1 \mathrm{SD}$ ), identified at age 9-24 months by a survey of poor neighbourhoods in Kingston.

Main results-Current weight was the strongest predictor of systolic blood pressure $(\beta=4.90 \mathrm{~mm} \mathrm{Hg} / \mathrm{SD}$ weight $95 \% \mathrm{CI}$ $3.97,5.83)$. Birth weight predicted systolic blood pressure $(\beta=-1.28 \mathrm{~mm} \mathrm{Hg} / \mathrm{SD}$ change in birth weight, $95 \%$ CI -2.17 , -0.38) after adjustment for current weight. There was a significant negative interaction between stunting in early childhood and current weight indicating a larger effect of increased current weight in children who experienced linear growth retardation in early childhood. There was no interaction between birth weight and current weight. The increase in blood pressure from age 7 to age 11-12 was greater in children with higher weight at age 11-12 and less in children with higher birth weight and weight at age 7 .
\end{abstract}

Conclusions-Birth weight predicted systolic blood pressure in Jamaican children aged 11-12. Postnatal growth retardation may potentiate the relation between current weight and blood pressure. Greater weight gain between ages 7 and 11 was associated with a greater increase in systolic blood pressure. The relation between growth and later blood pressure is complex and has prenatal and postnatal components.

(F Epidemiol Community Health 2001;55:394-398)

Barker and colleagues have suggested that there may be developmental periods in utero and in infancy during which inappropriate nutrition and poor growth lead to long term consequences for adult cardiovascular disease. ${ }^{12}$ Blood pressure in adults is typically inversely associated with birth weight. ${ }^{13}$ This inverse relation has also been described in childhood once adjustment is made for current size, ${ }^{4}$ although it has not been found in some populations. ${ }^{5}$ In two previous Jamaican studies blood pressure in childhood was related to maternal nutritional status ${ }^{6}$ and size at birth. ${ }^{7}$

Growth during infancy and early childhood may also influence later blood pressure. In a few studies, weight in infancy was not independently related to later blood pressure. ${ }^{8-10}$ These studies, conducted in the UK and France, would not have included many infants whose postnatal growth retardation was comparable to that experienced by many children in developing countries.

Many developing countries are experiencing an epidemiological transition from a pattern of primarily infectious diseases to increasing incidence of adult chronic diseases. ${ }^{11}$ It is possible that under-nutrition in childhood combined with better conditions in adulthood may contribute to the increasing levels of cardiovascular disease in these countries. ${ }^{12}$

In 1986 we began a longitudinal study of 127 children aged 9-24 months whose linear growth was retarded (stunted group, height for age $<-2$ SD of the NCHS references ${ }^{13}$ ), and a comparison group of children from the same poor communities in Kingston, Jamaica whose linear growth was normal (non-stunted group, height for age $>-1 \mathrm{SD}$ ). In the first two years of the study we evaluated the effects of supplementation and psychosocial stimulation on the stunted children's growth and mental development. ${ }^{14} 15$ The children were re-measured four years after the interventions ended when they were 7-8 years old. The height for age of the stunted children had increased from a mean of $-3.0 \mathrm{SD}$ scores on enrollment to $-1.1 \mathrm{SD}$ scores at follow up. ${ }^{16}$ This suggests that, after the period of early growth retardation, their growth was not limited by nutritional intakes.

This cohort of children who experienced early growth retardation followed by adequate growth provides an opportunity to further our understanding of the importance of growth, both in utero and postnatally, to later blood pressure. The objectives of this study were to determine whether at age 11-12 years the blood pressures of children who were stunted differed from those of children who were never stunted, and to determine the relations of birth weight and postnatal growth with blood pressure at age $11-12$.

\section{Methods}

PARTICIPANTS

The children were identified at age 9-24 months by house to house survey of several poor Kingston neighbourhoods. At that time, 127 stunted children (height for age $<-2$ SD 
of the NCHS references) and 32 non-stunted children (height for age $>-1$ SD) participated in a two year intervention study. The stunted group comprised all stunted children identified and the non-stunted children were matched to every fourth stunted child. Four years later, when the children were aged 7-8 years, we located 122 of the stunted children and all the non-stunted children for a follow up study of their growth and cognitive development. We also studied an additional 175 non-stunted children from the same neighbourhoods who had been identified during the original survey. ${ }^{17}$

At the current follow up 116 stunted children and 190 non-stunted children were located. Loss to follow up is attributable primarily to migration. Of the children located, five did not have their blood pressure measured because they now lived some distance from Kingston, giving a sample size of 112 stunted children and 189 non-stunted children $(91.5 \%$ of the children measured at age $7-8$ years).

The study was approved by the ethics committee of the University of the West Indies and the parents or guardians gave written informed consent for their children to participate.

MEASUREMENTS

Anthropometry

The children's height, weight, head and arm circumference and triceps and subscapular skinfolds were measured using standard procedures. ${ }^{18}$ Interobserver reliability was determined before beginning the study, and intraclass correlation coefficients exceeded 0.99 for all measures. Body mass index (weight $/$ height $^{2}$, BMI) was calculated and per cent body fat estimated from skinfolds with equations for black children using those for prepubescent and pubescent children as appropriate. ${ }^{19}$ Height for age was determined using the NCHS references. ${ }^{13}$ Birth weights were obtained from hospital records $(73 \%)$ or maternal recall and were available for all of the stunted children and 181 of the non-stunted children.

\section{Pubertal status}

The children's pubertal status was determined using the cut offs recommended by WHO, ${ }^{20}$ breast stage 2 for girls and genitalia stage 3 for boys. Children who have reached these stages have entered their pubertal growth spurt. The cut offs were therefore used to classify children into pre-pubertal and pubertal groups.

\section{Blood pressure}

Blood pressure was measured with a mercury sphygmomanometer after the child had been sitting relaxed for 10 minutes. Measurements were taken with the right arm, and arm circumference was measured to select the appropriate cuff size. Eighty nine per cent of the children were measured using the child/ small adult cuff, and the remaining children were measured with the adult cuff. Three measurements were taken, each two minutes apart, and the average of the last two used. The first and fifth Korotkoff sounds were recorded. All measurements were taken by the same observer. Reliability was measured with another observer in 26 children using a double headed stethoscope and the intraclass correlation coefficients were high (systolic $r=0.99$; diastolic $r=0.97$ )

\section{STATISTICAL ANALYSES}

Birth weight and current weight were converted to SD scores. Because of the sample selection procedure, weight at age 9-24 months was bimodal, furthermore, this measurement was not available for those non-stunted children enrolled at age 7 years. A dichotomous variable (stunted/non-stunted) was therefore used.

Multiple regression analyses were used to determine the effects of birth weight, linear growth retardation and current size on blood pressure. As recently recommended, ${ }^{21}$ the effects of early size and current size were first determined separately, then both early and current size were included in the regression. As a final step any interactions between early and current size were investigated to determine whether early size modified the effects of current size. Separate regressions were therefore computed for birth weight, current weight and nutritional status (stunted/non-stunted) at age 9-24 months. The effects of adjusting for current size and any interactions between earlier size and current size were then determined. As the stunted children had lower birth weights than the non-stunted children, birth weight was included in regressions investigating the effects of linear growth retardation at age 9-24 months to determine its effects independently of size at birth.

Preliminary regressions were conducted for the stunted and non-stunted groups separately and for pre-pubertal and pubertal children separately. The direction and magnitude of the slopes for birth weight did not differ significantly among the subgroups. The direction of the slopes for current size was always positive, however the magnitude of the regression coefficient was greater for the stunted children compared with the non-stunted children. The groups were therefore combined to increase statistical power and an interaction term used to confirm the difference in the effects of current weight in stunted and non-stunted children.

All regression models included current age, and sex. Current height was included in initial regressions but was never significant and its inclusion did not change the findings. Height was therefore omitted to simplify the models. Arm circumference, per cent body fat and pubertal status were offered stepwise in the final model.

The intervention in early childhood was a randomised trial of nutritional supplementation with or without psychosocial stimulation. ${ }^{14}$ There were no long term effects of supplementation on the children's size ${ }^{16}$ and no effects of supplementation on blood pressure. The interventions were therefore not considered further in the analyses. 
Table 1 Age, anthropometry, and blood pressure in stunted and non-stunted children

\begin{tabular}{|c|c|c|c|c|}
\hline & \multicolumn{2}{|c|}{$\begin{array}{l}\text { Stunted } \\
(n=112)\end{array}$} & \multicolumn{2}{|c|}{$\begin{array}{l}\text { Non-stunted } \\
(n=189)^{*}\end{array}$} \\
\hline & Mean & $S D$ & Mean & $S D$ \\
\hline Age (y) & 11.69 & 0.34 & 11.89 & 0.32 \\
\hline Height $(\mathrm{cm})$ & 141.3 & 6.1 & 153.4 & 6.2 \\
\hline Height for age (z score) & -1.01 & 0.83 & 0.52 & 0.81 \\
\hline Weight $(\mathrm{kg})$ & 32.82 & 5.77 & 43.07 & 8.85 \\
\hline Body mass index & 16.35 & 2.03 & 18.24 & 3.22 \\
\hline Arm circumference $(\mathrm{cm})$ & 20.2 & 2.2 & 22.4 & 3.0 \\
\hline Body fat $(\%) \dagger$ & 15.2 & 6.9 & 19.0 & 8.3 \\
\hline Birth weight $(\mathrm{kg}) \ddagger$ & 2.90 & 0.48 & 3.33 & 0.52 \\
\hline Systolic bp (mm Hg) & 100.4 & 8.7 & 106.4 & 8.5 \\
\hline Diastolic bp $(\mathrm{mm} \mathrm{Hg}) \S$ & 54.1 & 13.3 & 59.7 & 11.3 \\
\hline Adjusted systolic bp (mm Hg) & 104.2 & 9.7 & 104.1 & 9.2 \\
\hline Adjusted diastolic bp (mm Hg) & 57.7 & 15.0 & 57.5 & 14.0 \\
\hline
\end{tabular}

*Non-stunted significantly greater than stunted, all $\mathrm{p}<0.001$, except adjusted systolic and diastolic blood pressures. †Nonstunted $(n=187)$. $¥$ Non-stunted $(n=181)$. $\ n=104$ for stunted group, no measurable diastolic pressure in eight children. IAdjusted for age, weight, and height.

\section{Results}

The mean age of the non-stunted children was slightly greater (approximately 2.5 months, $\mathrm{p}<$ 0.001 ) and they were significantly larger than the stunted children in all anthropometric measurements (table 1 ). In the stunted group $57.1 \%(n=64)$ of the children were boys and in the non-stunted group $53.4 \%(n=101)$ were boys.

The stunted children had caught up in height relative to the NCHS references, $48.2 \%$ of them now had heights for age $>-1 \mathrm{SD}$ and only $11.6 \%$ still had heights for age $<-2$ SD. The BMI distribution of the non-stunted children approximated that of the US black population $^{22}$ with $4.2 \%$ below the 5 th percentile (thin) and $16.4 \%$ above the 85 th centile (overweight). Few of the stunted children were overweight $(4.5 \%)$ while $18.7 \%$ of them were thin according to the centiles for US blacks.

Significantly more of the non-stunted children $(59.9 \%)$ had entered their pubertal growth spurt than the stunted children $(39.3 \%, \mathrm{p}<0.001)$. More girls $(87.5 \%)$ than boys $(22.7 \%, \mathrm{p}<0.001)$ were in puberty.

The non-stunted children had significantly higher systolic and diastolic blood pressures than the stunted children (table 1). These differences were no longer apparent after adjustment for age, weight, and height.

PREDICTORS OF BLOOD PRESSURE

Multiple regression analyses of systolic blood pressure on birth weight and weight at age 11-12 are given in table 2 . Birth weight was significantly related to systolic blood pressure only after adjustment for current weight. The effect of 1 SD change in current weight was 3.8 times that of an SD change in birth weight. The addition of birth weight to a model containing
Table 3 Multiple regression of systolic blood pressure on birth weight, current weight, and nutritional status at age 9-24 months*

\begin{tabular}{lll}
\hline & $\beta$ & $95 \% C I$ \\
\hline Birth weight & -1.32 & $-2.21,-0.42$ \\
Weight at 11-12 years & 5.22 & $4.05,6.39$ \\
Stunted/non-stunted at 9-24 months & -0.50 & $-2.93,1.93$ \\
Interactiont & -2.61 & $-5.13,-0.10$ \\
$r^{2}$ & 0.33 \\
\hline
\end{tabular}

${ }^{\star}$ Adjusted for sex and current age, birth weight and weight at age 11-12 years expressed as SD scores. Stunted $=0$, non-stunted $=1 .+$ Interaction $=$ stunted/non-stunted $\times$ weight at $11-12$ years.

Table 4 Multiple regression of diastolic blood pressure on birth weight, current weight, and nutritional status at age 9-24 months*

\begin{tabular}{lll}
\hline & $\beta$ & $95 \% C I$ \\
\hline Birth weight & 0.76 & $-0.66,2.17$ \\
Weight at 11-12 years & 4.18 & $2.31,6.05$ \\
Stunted/non-stunted at 9-24 months & -0.51 & $-4.33,3.30$ \\
Interaction $\dagger$ & -6.28 & $-10.32,-2.23$ \\
$r^{2}$ & & 0.13
\end{tabular}

*Adjusted for sex and current age, birth weight and weight at age 11-12 years expressed as SD scores. Stunted $=0$, non-stunted $=1$. Interaction $=$ stunted $/$ non-stunted $\times$ weight at $11-12$ years.

age, sex, and current weight resulted in a modest but significant increase in the variance explained from $30 \%$ to $32 \%$. The interaction between birth weight and current weight was not significant.

Early childhood growth retardation had no significant main effect on systolic blood pressure after adjustment for birth weight and current weight (table 3). However, there was a significant negative interaction between early childhood growth retardation and current weight, indicating larger effects of increasing weight at age 11-12 years in children who were stunted at age 9-24 months. There was no significant interaction between birth weight and growth retardation in early childhood.

Arm circumference, per cent body fat and pubertal status were offered stepwise after the variables in the above model were entered. They made no additional contribution to the variance in systolic blood pressure.

The same regression analyses were conducted with diastolic blood pressure as the dependent variable. Birth weight was not significantly related to diastolic blood pressure either with or without adjustment for current weight. Weight at 11-12 years predicted diastolic pressure and the interaction between early childhood growth retardation and weight was also significant (table 4).

\section{Childhood overweight}

It has been suggested that the effect of birth weight is most strongly expressed in individuals who become overweight. ${ }^{23}$ As the number of

Table 2 Multiple regressions of systolic blood pressure at age 11-12 years on birth weight, and weight at age 11-12 years *

\begin{tabular}{|c|c|c|c|c|c|c|c|c|}
\hline & $\beta$ & $95 \% C I$ & $\beta$ & $95 \% C I$ & $\beta$ & $95 \% C I$ & $\beta$ & $95 \% C I$ \\
\hline Birth weight & -0.75 & $-1.79,0.29$ & & - & -1.28 & $-2.17,-0.38$ & -1.27 & $-2.16,-0.38$ \\
\hline Weight at $11-12$ years & & - & 4.75 & $3.82,5.69$ & 4.90 & $3.97,5.83$ & 4.92 & $3.99,5.85$ \\
\hline Interaction & & - & & - & & - & -0.62 & $-1.52,0.29$ \\
\hline$r^{2}$ & & 0.06 & & 0.30 & & 0.32 & & 0.32 \\
\hline
\end{tabular}

*All models include sex and current age, birth weight and weight at age 11-12 years expressed as SD scores. $\dagger$ Interaction $=$ birth weight $\times$ weight $11-12$ years. 
Table 5 Multiple regression of systolic blood pressure at age 11-12 years on birth weight, current weight, and systolic blood pressure and weight at age 7 years*

\begin{tabular}{lll}
\hline & $\beta$ & $95 \% C I$ \\
\hline Birth weight & -1.05 & $-1.83,-0.27$ \\
Weight at 7 years & -1.82 & $-3.29,-0.35$ \\
Weight at 11-12 years & 4.55 & $3.08,6.02$ \\
Systolic blood pressure at 7 years & 0.49 & $0.39,0.58$ \\
$r^{2}$ & & 0.50 \\
\hline
\end{tabular}

*Adjusted for sex and current age, birth weight and weight at age 7 years and $11-12$ years expressed as SD scores.

overweight children was too small for separate analysis we repeated the analyses excluding the 34 overweight children. Birth weight was still negatively associated with systolic blood pressure after adjustment for current weight and the size of the regression coefficient was little changed $(\beta=-1.30,95 \%$ CI $-2.25,-0.34)$

CHANGE IN SYSTOLIC BLOOD PRESSURE

The mean (SD) increase in systolic blood pressure since the previous measurements at age $7-8$ years was similar in the stunted $(7.9$ (7.6) $\mathrm{mm} \mathrm{Hg}$ ) and non-stunted children (8.0 (8.2) $\mathrm{mm} \mathrm{Hg}$ ). To look at change in blood pressure we repeated the regression analyses controlling for systolic blood pressure at age 7-8 years (table 5). Children with higher weight at 11-12 years had greater increases in blood pressure from age 7 to age 11-12 years, while children with higher birth weight and weight at age 7 years had smaller increases.

\section{Discussion}

After adjusting for current size there was no difference in systolic or diastolic blood pressure between stunted and non-stunted children. However, the effect of increased weight at age 11-12 years, on both systolic and diastolic blood pressure, was greater among children who experienced linear growth retardation in early childhood. Thus while there seems to be no direct relation between stunting and later blood pressure, stunting may modify the effect of later weight gain.

One third of children in developing countries become growth retarded before the age of 5 years. ${ }^{24}$ If linear growth retardation potentiates the effects of later weight gain on blood pressure then stunting in early childhood may be an important contributor to the rise in cardiovascular disease in developing country populations undergoing the epidemiological transition. This may be particularly so where growth retarded children become overweight adults.

The expected negative association was observed between systolic blood pressure and birth weight after adjustment for current weight. $^{3472526}$ It remains unclear whether this relation is attributable to size at birth or to the change in relative size from birth to age 11-12 years. ${ }^{21}$ The relation between birth weight and diastolic blood pressure is less consistent, with negative associations reported, ${ }^{1025}$ associations only in girls ${ }^{27}$ or boys ${ }^{28}$ or no associations. ${ }^{526} 29$ No significant relation between birth weight and diastolic blood pressure was observed in this study.
KEY POINTS

- Childhood growth retardation may amplify the effect of weight on blood pressure and contribute to the rise in cardiovascular disease in developing countries.

- Postnatal growth retardation did not change the negative association between birth weight and blood pressure.

- Blood pressure increased more from age 7-11 years in children with lower birth weights.

- Weight gain from age 7 to 11 years is associated with the change in blood pressure during this period.

The association between birth weight and systolic blood pressure was seen despite $52 \%$ of the children having entered their pubertal growth spurt. It has been suggested that rapid growth during puberty and differing maturation rates may disrupt the tracking of blood pressure and for this reason a significant relation between birth weight and blood pressure has not been found in some studies of adolescents ${ }^{2930}$ although in one study in which pubertal stage was assessed, significant inverse associations were found in pubertal but not pre-pubertal children. ${ }^{9}$ In the current study pubertal status did not contribute to the variance in blood pressure, however, the children were classified only by whether or not they had begun their pubertal growth spurt and this was thus a relatively crude index.

Linear growth retardation in the first two years of life did not change the effects of birth weight on later blood pressure. Whincup et $a l^{10}$ reported a stronger relation between birth weight and systolic blood pressure at age 3 years in children who were shorter at that time. Few children in that study would have experienced the degree of linear growth retardation ( $<-2 \mathrm{SD}$ height for age) observed in children in our study. Further work is needed on the extent to which postnatal growth may modify the relation between birth weight and blood pressure.

The relation between birth weight and blood pressure was not driven by a stronger relation in those children who had become overweight as omitting them for the analyses did not diminish the regression coefficient for birth weight. Thus, unlike the suggestions for adults, ${ }^{23}$ our results indicate that the association between birth weight and blood pressure is seen in children within the normal weight range. The effect of current weight on systolic blood pressure was about four times that of birth weight, similar to findings for children in the UK aged $8-11$ years. ${ }^{27}$

The increase in systolic pressure between measurements at age 7 and 11 years was greater in children with lower birth weight. Similar findings were reported in children in the UK measured at age 5-7 years and again at 9-11 years. ${ }^{25}$ Children who were larger at age 7 years had smaller increases in systolic blood pressure between ages 7 and 11 years. 
Adjusting for weight at age 7 years, a higher weight at age 11 years was associated with a larger increase in blood pressure from age 7-11 years. Thus size at birth, in infancy and childhood may all be associated with later blood pressure. Studies of the impact of early growth on later blood pressure are limited by the emphasis on birth weight and need to also include measures of postnatal and childhood size.

In conclusion, birth weight was a significant predictor of blood pressure in Jamaican children, once current weight was controlled. Postnatal growth retardation may modify the relation between current weight and blood pressure. The relation between early growth and blood pressure is thus not restricted to size at birth and further studies are needed that include measures of size during childhood to fully describe these relations.

Funding: the study was supported by the Wellcome Trust

(Grant no. 049235/Z/96/Z).
Conflicts of interest: none.

1 Barker DJP, Osmond C, Golding J, et al. Growth in utero, blood pressure in childhood and adult life, and mortality from cardiovascular disease. BMF 1989;298:564-7.

2 Barker DJP, Osmond C, Winter PD, et al. Weight in infancy and death from ischaemic heart disease. Lancet 1989:ii: 577-80.

3 Law CM, Shiell AW. Is blood pressure inversely related to birth weight? The strength of evidence from a systematic review of the literature. F Hypertens 1996;14:935-41.

4 Whincup PH. Fetal origins of cardiovascular risk: evidence from studies in children. Proc Nutr Soc 1998;57:123-7.

5 Donker GA, Labarthe DR, Harrist RB, et al. Low birth weight and blood pressure at age $7-11$ years in a biracial weight and blood pressure at age 7-11 year 7 Epidemiol 1997;145:387-97.

6 Godfrey KM, Forrester T, Barker DJP, et al. Maternal nutritional status in pregnancy and blood pressure in childhood. tional status in pregnancy and blood pre
Br $\mathcal{F}$ Obstet Gynaecol 1994;101:398-403.

7 Forrester TE, Wilks RJ, Bennett FI, et al. Fetal growth and cardiovascular risk factors in the West Indies. $B M \mathcal{F}$ 1996;312:156-60.

8 Law CM, de Sweit M, Osmond C, et al. Initiation of hypertension in utero and its amplification throughout life. $B M \mathcal{F}$ 1993;306:24-7.

9 Zureik M, Bonithon-Kopp C, Lecomte E, et al. Weights at birth and in early infancy, systolic pressure, and left ventricular structure in subjects 8 to 24 years. Hypertension 1996;27:339-45.

10 Whincup PH, Bredow M, Payne F, et al. Size at birth and blood pressure at 3 years of age. The Avon Longitudina Study of Pregnancy and Childhood (ALSPAC). Am $\mathcal{F}$ Epidemiol 1999;149:730-9.

11 Popkin BM. The nutrition transition and its health implications in lower-income countries. Public Health Nutr 1998;1: tions in 21 .
2 Barker DJP. Mothers, babies and health in later life. 2nd ed. Edinburgh: Churchill Livingstone, 1998:97-115.

13 Hamill PVV, Drizd TA, Johnson CL, et al. NCHS growth curves for children, birth-18 years. Vital and Health Statistics Series 11 , no 165 . DHEW publ no (PHS) 78-1650. Hyatsville MD: Department of Health and Human Services, 1977.

14 Grantham-McGregor SM, Powell CA, Walker SP, et al. Nutritional supplementation, psychosocial stimulation and development of stunted children: The Jamaican study. Lancet 1991;338:1-5.

15 Walker SP, Powell CA, Grantham-McGregor SM, et al. Nutritional supplementation, psychosocial stimulation and growth of stunted children: The Jamaican study. Am $\mathcal{F}$ Clin Nutr 1991;54:642-8.

16 Walker SP, Grantham-McGregor SM, Himes JH, et al. Early childhood supplementation does not benefit the long-term growth of stunted children in Jamaica. F Nutr 1996;126: 3017-24.

17 Gaskin P. Early childhood linear growth retardation and its effects on blood pressure and lung function in later childhood. $[\mathrm{PhD}$ thesis]. Kingston: University of the West Indies, Jamaica, 1998.

18 Lohman TG, Roche AF, Martorell R, eds. Anthropometric standardization reference manual. Champaign IL: Human Kinetics, 1988.

19 Slaughter MH, Lohman TG, Boileau RA, et al. Skinfold equations for estimation of body fatness in children and youth. Human Biol 1988;60:7009-23.

20 World Health Organization. Physical status: the use and interpretation of anthropometry. WHO Technical report series 854. Geneva: World Health Organization, 1995:263311.

21 Lucas A, Fewtrell MS, Cole TJ. Fetal origins of adult disease-the hypothesis revisited. BMF 1999;319:245-9.

22 Must A, Dallal GE, Dietz WH. Reference data for obesity: 85th and 95th percentiles of body mass index $\left(\mathrm{wt} / \mathrm{ht}^{2}\right)$ and triceps skinfold thickness. Am f Clin Nutr 1991;53:839-46.

23 Leon DA, Koupilova I, Lithell HO, et al. Failure to realise growth potential in utero and adult obesity in relation to blood pressure in 50 year old Swedish men. BMF 1996;312:401-6.

24 United Nations Administrative Committee on Coordination. Sub-committee on Nutrition(ACC/SCN). Fourth Report on the World Nutrition Situation. Geneva: ACC/SCN/ IFPRI, 2000.

25 Whincup PH, Cook DG, Papacosta O. Birth weight and blood pressure; cross sectional and longitudinal relationships in childhood. BMF 1995;311:773-6.

26 Levitt NS, Steyn K, De Wet T, et al. An inverse relation between blood pressure and birth weight among 5 year old children from Soweto, South Africa. F Epidemiol Community Health 1999;53:264-8.

27 Taylor SJC, Whincup PH, Cook DG, et al. Size at birth and blood pressure: cross sectional study in 8-11 year old children. BMF 1997;314:475-80.

28 Taittonen L, Nuutinen M, Turtinen J, et al. Prenatal and postnatal factors in predicting later blood pressure among children: Cardiovascular risk in young Finns. Pediatr Res 1996;40:627-32

29 MacIntyre S, Watt G, West P, et al. Correlates of blood pressure in 15 year olds in the west of Scotland. I Epidemiol Community Health 1991;45:143-7.

30 Matthes JWA, Lewis PA, Davies DP, et al. Relation between birth weight at term and systolic blood pressure in adolescence. BMF 1994;308:1074-7. 